\title{
What is best practice when conducting the decision-making capacity assessment of patients in the hospital?
}

\author{
Tracy Sheldrick ${ }^{1}$, Alex Barwick ${ }^{2}$, Paul Butterworth ${ }^{2}$, and Nasim Salehi ${ }^{2}$ \\ ${ }^{1}$ Bendigo Health \\ ${ }^{2}$ Southern Cross University
}

July 20, 2020

\begin{abstract}
The capacity to make reasoned decisions about one's health care is central to optimal person-centered care. Termed 'decisionmaking capacity', it requires comprehension of the information presented about one's health, an understanding of one's circumstances and the reasoning skills to navigate health care options. Impaired decision-making capacity is prevalent in hospital settings whilst also being under-recognized leading to sub-optimal care and raising ethical concerns. This assesses decisionmaking capacity all the more important in this setting. This scoping review aimed to explore and summarise the literature on current practice in the assessment of decision-making capacity in hospital settings. A total of four databases (Psychinfo, CINAHL, Scopus and Medline) were searched from 2009 to June 2019, using search terms related to 'assessment', 'decisionmaking capacity' and 'patient'. Thirteen studies were included. They investigated a variety of methods for assessing decisionmaking capacity in hospital settings. No gold standard test emerged. Commonly, it was doctors that assessed decision-making capacity with an informal interview with the patient; however, the error rate for this assessment was up to $58 \%$. The literature suggests that training in this method and/or the use of more structured assessment tools may be required to improve the accuracy of decision-making capacity assessment. Another finding was that decision-making capacity assessments rely heavily on patient communication abilities. Therefore, all efforts should be made to provide communication assistance, for support with patients who have complex communication needs (including engagement with Speech and Language Pathology services). Finally, healthcare services must ensure health professionals performing capacity assessments receive appropriate training and that robust policy are in place to support improved assessment practices.
\end{abstract}

What is best practice when conducting the decision-making capacity assessment of patients in the hospital?

Tracy Sheldrick ${ }^{a *}$, Alex Barwick, Paul Butterworth, Nasim Salehi

${ }^{a}$ Tracy Sheldrick, Manager Speech Pathology and Audiology, Bendigo Health, Victoria, Australia. Masters of Healthcare Leadership, Southern Cross University, Australia. Email; tsheldrick@bendigohealth.org.au, Twitter; @Tsheldrick,Phone (03) 54547162

Dr Alex Barwick, School of Health and Human Sciences, Southern Cross University, Bilinga, Queensland, Australia

Dr Paul Butterworth, School of Health and Human Sciences, Southern Cross University, Bilinga, Queensland, Australia

Dr Nasim Salehi, School of Health and Human Sciences, Southern Cross University, Bilinga, Queensland, Australia

Tracy Sheldrick is Manager of Speech Pathology and Audiology at Bendigo Health in Australia currently studying Masters of Healthcare Leadership through Southern Cross University 
Funding details: This project was undertaken as part of the Masters of Healthcare Leadership, Southern Cross University. No funding

Disclosure statement: No potential conflict of interest was reported by the authors.

Word count: 3,820 excluding tables and references

Table 1. Databases and search terms used to identify literature for review

Table 2. Key methodological features and findings from reviewed studies of quantitative studies

Table 3. Key methodological features and findings from reviewed studies of qualitative studies

Figure 1. PRISMA flow diagram, Adapted from PRISMA, 2015

\section{Hosted file}

IJCP structured Abstract final.docx available at https://authorea.com/users/343692/articles/ 470318-what-is-best-practice-when-conducting-the-decision-making-capacity-assessment-ofpatients-in-the-hospital

\section{Hosted file}

IJCP Main text final.docx available at https://authorea.com/users/343692/articles/470318what-is-best-practice-when-conducting-the-decision-making-capacity-assessment-ofpatients-in-the-hospital

\section{Hosted file}

IJCP figures.docx available at https://authorea.com/users/343692/articles/470318-what-isbest-practice-when-conducting-the-decision-making-capacity-assessment-of-patients-inthe-hospital 